"Eres el héroe que no morirá jamás...". El Soldado Desconocido: política y memoria de la Gran Guerra en Italia Marina CARDOZO

Avances del Cesor, V. XV, № 18, junio 2018, pp. 83-107.

ISSNe 2422-6580 / ISSN 1514-3899 - http://web2.rosario-conicet.gov.ar/ojs/index.php/AvancesCesor/index

\title{
"Eres el héroe que no morirá jamás..."1 El Soldado Desconocido: política y memoria de la Gran Guerra en Italia ${ }^{2}$ \\ "You are the hero who will never die..." The Unknown Soldier: politics and memory of the Great War in Italy
}

\author{
Marina Cardozo \\ Universidad de la República \\ Uruguay \\ dulcimarina@gmail.com
}

\section{Resumen}

El largo aniversario de la Gran Guerra -iniciado en 2014 y destinado a continuar hasta 2018- ha relanzado los mitos creados por el régimen liberal, amplificados por el fascismo y conservados luego en democracia. Este artículo se ocupa de analizar la construcción de la figura del Soldado Desconocido en Italia, desde su institución durante el régimen liberal y hasta el advenimiento de la república democrática, luego del fin del fascismo. Las conmemoraciones dedicadas al Soldado Desconocido, organizadas en varias naciones participantes de la guerra, consagraron una estrategia de sacralización de la guerra, en el marco de una eficaz política de redefinición de la memoria. El caso italiano es particularmente importante, porque las ceremonias que en 1921 llevaron el ataúd del Soldado Desconocido al Altare della Patria, en el centro de Roma, coincidieron con la fundación del Partito Nazionale Fascista. Luego Mussolini completará el proceso de fascistización retroactiva de la guerra, con una ola de monumentos a los caídos y la construcción de enormes osarios en las zonas que habían sido escenario de combates. En el pasaje de la dictadura a la democracia, el Soldado Desconocido permaneció como elemento de referencia en los ritos oficiales y en el imaginario colectivo.

Palabras Clave: Memoria, Política, Soldado Desconocido, Italia, Primera Guerra Mundial

1. Verso del himno Soldato Ignoto (1921) compuesto por músico y escritor napolitano E. A. Mario (pseudónimo de Giovanni Gaeta).

2. Agradezco al Profesor Emilio Franzina por sus inestimables sugerencias y orientaciones, que han enriquecido el presente texto. 


\begin{abstract}
The long anniversary of the Great War - which initiated in 2014 and continued until 2018 - has relaunched the myths created by the liberal regime, amplified by fascism and then preserved in democracy. This article deals with analyzing the construction of the figure of the Unknown Soldier in Italy, from his institution during the liberal regime until the advent of the democratic republic, after the end of fascism. The Unknown Soldier commemorations, organized in several nations participating in the war, consecrated a strategy of sacralization of the war, within the framework of an effective policy of memory redefinition. The Italian case is particularly important, because the ceremonies carry out during 1921 when the coffin of the Unknown Soldier was laid to rest in the Altare della Patria, in the center of Rome, coincided with the founding of the Partito Nazionale Fascista. Then Mussolini will complete the retroactive fascistization process of the war, with a constructing wave of memorials to the fallen and the building of huge ossuaries in the areas that had been scenes of battles. In the passage from dictatorship to democracy, the Unknown Soldier remained a reference element in official rites and in the collective imagination.
\end{abstract}

Key Words: Memory, Politics, Unknown Soldier, Italy, First World War

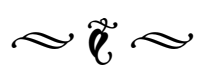

\section{Introducción}

\section{Aniversarios e historiografía}

Uno de los historiadores militares italianos más destacados, Giorgio Rochat, observaba en 2010: "la memoria nacional parece haber olvidado ya la Gran Guerra". ${ }^{3}$ En efecto, desde un tiempo atrás, en Italia, el tema interesaba a unos pocos especialistas, y las publicaciones sobre la Gran Guerra eran poco frecuentes, destinadas a una circulación reducida. Luego, a raíz del largo centenario del conflicto europeo, los medios de masas prontamente remediaron la prolongada desatención, y a partir del año 2014, las librerías italianas (así como también aquellas de otros países europeos), se colmaron de una impresionante cantidad de volúmenes sobre el tema.

3. BREGANTIN, Lisa, Per non morire mai. La percezione della morte in guerra e il culto dei caduti nel primo conflitto mondiale, Il Poligrafo, Vicenza, 2010, p. 10.

84
Con las señaladas excepciones, se trata de textos en buena medida reiterativos y sin novedades historiográficas significativas, que buscan atraer la atención y curiosidad de los lectores y -quizás por esto- presentan este trágico evento histórico a través de miradas que oscilan entre lo nostálgico, lo admirativo y lo patriótico-nacionalista. Esta bulimia bibliográfica, previsiblemente proseguirá hasta el año 2018 para luego casi seguramente extinguirse en forma progresiva.

Podemos determinar una sucesión de cuatro momentos historiográficos vinculados, a su vez, a cuatro generaciones de expertos en el estudio de la Gran Guerra en Italia.

En una primera instancia, se ocuparon del tema algunos militares (generales y oficiales como Enrico Caviglia, Emilio Faldella, Angelo Gatti, Gaetano Giardino y otros), y ciertos intelectuales enrolados en forma voluntaria 
(entre los cuales destaca el modernista Gioacchino Volpe). Su aproximación fue sustancialmente un intento de legitimar la guerra y reivindicar el sacrificio de los combatientes. Esta fase, condicionada por las directivas de la dictadura mussoliniana -que, apropiándose de la "victoria” presentaba la Gran Guerra como el inicio de la recuperación nacional después culminada en la marcia su Roma del 28 de octubre de 1922-, ha producido imponentes cementerios-osarios y una cantidad innumerable de monumentos a los caídos, lugares de realización de ceremonias conmemorativas por parte del régimen fascista, acompañadas de una gran participación popular.

Con el derrumbe del fascismo, los veinte años que transcurren desde el fin de la Segunda Guerra Mundial hasta mediados de la década del sesenta, se caracterizaron por la carencia de nuevos estudios significativos, hasta 1965, cuando en el marco de las conmemoraciones por la entrada de Italia en el conflicto, uno de los más notorios historiadores militares de la generación integrada por quienes habían combatido en la guerra, Piero Pieri (1893-1979), de orientación democrática, publicó en tres diversas ediciones el importante trabajo de síntesis L'Italia nella prima guerra.

La tercera fase se abre en 1968, cincuentenario del fin de la guerra y año símbolo de la rebelión juvenil, que estalla en Francia difundiéndose luego en Italia y Alemania, con el protagonismo del movimiento estudiantil y la apertura de un fuerte ciclo de luchas obreras. En dicho año se publicó Plotone di esecuzione, antología de sentencias de los tribunales militares que aplicaron la pena de muerte a soldados, principalmente desertores. La publicación, a cargo de Enzo Forcella y Alberto Monticone, ${ }^{4}$ generó notable conmoción: por primera vez se documentó el disenso dentro de la guerra y su implacable represión.

Contemporáneamente, algunos historiadores jóvenes ligados al movimiento de la Nueva Izquierda italiana (como Antonio Gibelli, Mario Isnenghi y Giorgio Rochat), criticaron radicalmente las versiones patrióticas del conflicto prevalecientes hasta el momento. La revisión historiográfica fue acompañada en forma significativa, por el filme Uomini contro (1971), dirigido por el cineasta napolitano Francesco Rosi e inspirado en la autobiografía del destacado intelectual antifascista Emilio Lussu, $U n$ anno sull'altipiano, que fuera publicada en su exilio parisino, en 1938. En el marco de esta revisión ideológico-historiográfica, atenta a los aspectos sociales y políticos de la guerra, se produjo un deterioro de la visión impuesta por anteriores mitificaciones, y maduraron, también desde la opinión pública, perspectivas críticas sobre la conflagración mundial.

Con el nuevo milenio, emergió una cuarta generación de historiadores (entre los cuales se encuentran Daniele Ceschin, Paolo Ferrari, Giovanna Procacci, Nicola Labanca, Diego Leoni), sensibles a ciertos aspectos menos estudiados de la guerra (deserción, afecciones de orden psico-físico en combatientes, vínculos oficialidad-tropa), y a la relación entre militares y sociedad civil.

Por último, como se ha indicado, a raíz del centenario se han incrementado las rememoraciones, caracterizadas por imponentes celebraciones oficiales, producción de filmes y pro-

4. FORCELLA, Enzo y MONTICONE, Alberto (compiladores) Plotone di esecuzione. I processi della prima guerra mondiale, Laterza, Roma-Bari, 1968. 
gramas de radio y televisión, todo ello sumado a una densa producción bibliográfica. Para dar una idea del aluvión editorial en relación con la Gran Guerra, considérese que, en torno a la debacle de Caporetto, del 24 de octubre de 1917, solamente en el primer semestre de 2017 se publicaron una veintena de volúmenes, alguno de los cuales, incluso, presentaron ese revés contundente en tanto que victoria decisiva.

El núcleo central de este trabajo, consiste en explorar un aspecto particular ligado a la memoria de la Gran Guerra, como la creación $y$ transformaciones producidas en una de las elaboraciones conmemorativas claves de la experiencia de guerra, el denominado Soldado Desconocido. La construcción del Soldado Desconocido, como parte esencial de las políticas oficiales de conmemoración de la Gran Guerra en Europa, fue particularmente potente en Gran Bretaña y Francia, ostentando asimismo un lugar muy destacado en el proceso político italiano posterior a la finalización de la guerra.

La figura del Soldado Desconocido, o Milite Ignoto en Italia, ha sido gestionada estratégicamente a nivel institucional por el Ministerio de Defensa, las asociaciones militares y otros, con una rememoración oficial de tipo retórico-conmemorativo, asociada cada año a la fecha del 4 de noviembre, aniversario del fin del conflicto. El 4 de noviembre recuerda el día de la victoria italiana en la Gran Guerra, y simbólicamente, la victoria en todas las guerras. Se puede interpretar esta celebración como resarcimiento simbólico en virtud de las derrotas sufridas por el ejército regular italiano en importantes batallas libradas en diferentes guerras: durante el proceso de la unificación nacional, en Custoza (22 al 27 de julio de 1848) y en Lissa (20 de julio de 1866); en las guerras coloniales (Adua, 1 de marzo de 1896); y especialmente, como se ha señalado, en la Primera Guerra Mundial, con la retirada de Caporetto.

Instituido por el agonizante régimen liberal entre octubre y noviembre de 1921, el Soldado Desconocido fue valorizado por los gobiernos fascistas (31 de octubre de 1922 -25 de julio de 1943) y actualizado por la república democrática desde 1946 a nuestros días. En síntesis, tres sistemas políticos sucesivos, congregados -si bien en diferente forma y medida- en torno a la estrategia de sacralización de la guerra, de la cual la conmemoración del Milite Ignoto constituye una pieza medular. Este texto busca por ello, interpretar las formas de recordar la guerra a través de los sentidos otorgados a lo largo del tiempo a la figura del Soldado Desconocido, en el sentido señalado por Elizabeth Jelin cuando observa que es necesario "pensar los procesos de memoria como parte de un devenir que implica cambios y elaboraciones en los sentidos que los actores específicos dan a esos pasados". 5

Para comprender la importancia de la construcción del Milite Ignoto a través del tiempo, es necesario considerar que la Primera Guerra Mundial representa en el siglo XX, el factor aglutinante y principal elemento nacionalidentitario que sustituye al Risorgimento en tanto que representación y símbolo de unidad nacional en el imaginario social, en el sentido otorgado a esta noción por el historiador polaco Bronislaw Baczko. ${ }^{6}$ La Resistencia contra el nazifascismo, por el contrario, ha sido his-

\footnotetext{
5. JELIN, Elizabeth, La lucha por el pasado. Como construimos la memoria social, Siglo XXI, Buenos Aires, 2016, p. 18.

6. BACZKO, Bronislaw, Los imaginarios sociales. Memorias y esperanzas colectivas, Nueva Visión, Buenos Aires, 1999, pp. 7-8.
} 
tóricamente objeto de polémicas y divisiones, disputas que se continúan hasta el presente. ${ }^{7}$

Frente a las ceremonias oficiales vinculadas al Milite Ignoto, se construyó un silencio oficial (fundamentalmente de parte de fascismo), que buscaba extirpar y remover los aspectos antiheroicos de la guerra, en particular el tema de la deserción en el frente, relevante sobre todo en el año $1917,{ }^{8}$ y que suscitara una sangrienta represión ejecutada través de fusilamientos sumarios. El recuerdo en torno a deserciones y fusilamientos fue censurado durante el período fascista y "olvidado" luego durante la Repúbli$\mathrm{ca}$, aunque puede decirse que una contra-memoria minoritaria, opuesta a las políticas de conmemoración oficial -o memoria subterránea, en el sentido en que la define Michael Pollak-, ${ }^{9}$ se sostuvo a través del tiempo para emerger ocasionalmente en coyunturas determinadas, en especial en los años-aniversario. ${ }^{10}$

7. Al respecto de las memorias en disputa sobre la Resistencia en Italia, véase el sugerente artículo de Alessandro Portelli. PORTELLI, Alessandro, "Memoria e identidad. Una reflexión desde la Italia post-fascista", en JELIN, Elizabeth y LANGLAND, Victoria (compiladoras) Monumentos, memoriales y marcas territoriales, Siglo XXI, Madrid, 2003, pp. 165-190.

8. Marc Ferro indica una cifra de 56.268 desertores solamente en 1917. FERRO, Marc, La Gran Guerra 1914-1918, Alianza, Madrid, 1984, p. 350.

9. POLLAK, Michael, Memoria, olvido, silencio. La producción social de identidades frente a situaciones limite, $\mathrm{Al}$ Margen, La Plata, 2006, pp. 17-18.

10. Ejemplo de la esporádica irrupción de memorias subterráneas de carácter antimilitarista, fueron las repercusiones del espectáculo Bella ciao, realizado en junio de 1964 en el marco del Festival dei due mondi, en Spoleto (Umbria), en un nuevo aniversario de la guerra. $\mathrm{La}$ interpretación de la conocida balada popular Gorizia tu sia maledetta, por el conjunto musical Nuovo Canzoniere Italiano, produjo reacciones fuertemente encontradas, culminando finalmente en un proceso judicial contra el grupo musical, por agravio a las instituciones. La canción,
Se examinarán dos ejemplos de lo expuesto. En primer lugar, la inauguración en 2004 (nonagésimo aniversario del inicio de la Gran Guerra), en Rovereto (localidad ubicada en la zona del Trentino), de un monumento dedicado al Disertore Ignoto, en una acción política llevada adelante por un grupo de pacifistas organizados. Las autoridades ordenaron su inmediata remoción al tiempo que Sandro Canestrini, orador del evento, fue denunciado por vilipendio a las fuerzas armadas. En segundo término, la publicación de la novela La storia (quasi) vera del milite ignoto (2014), por el historiador vicentino Emilio Franzina, uno de los expertos italianos más notorios en el estudio de las migraciones del siglo XIX. Concebida como "autobiografía" desmitificadora, se trata de una reflexión crítica sobre la construcción del Soldado Desconocido. El autor ha publicado también numerosas investigaciones sobre historia social y cultural de la Primera Guerra Mundial, por lo cual no deja de ser indicativo de la fuerza simbólica y del arraigo de la figura del Milite Ignoto en la memoria colectiva, la elección del género novela histórica a los efectos de contribuir a la reflexión crítica de la memoria dominante de la Gran Guerra. de autor anónimo y creada en el frente de batalla luego de los sangrientos combates de agosto de 1916, constituye una denuncia de la guerra y de la responsabilidad de las autoridades en el conflicto: Traditori signori ufficiali che la guerra l'avete voluta / scannatori di carne venduta e rovina della gioventù... ("Traidores señores oficiales, que han querido la guerra/ degolladores de carne vendida y ruina de la juventud". Traducción propia).

Véase el texto íntegro de la canción. Disponible en: <https://www.antiwarsongs.org/canzone. php?id=47\&lang=en>. 


\section{Memorias en conflicto}

Después de la victoria sobre el Imperio austrohúngaro del 4 de noviembre de 1918, Italia se precipita en una fase de profunda laceración social y política. La herencia de la guerra resultó tan dura y decisiva, y tan importante fue la difusión del antimilitarismo, ${ }^{11}$ que llevaron al gobierno de Francesco Saverio Nitti a no celebrar el primer aniversario de la victoria, oficialmente por razones organizativas ligadas al inminente proceso electoral. ${ }^{12}$ Muy diversa era la situación en Francia, donde -para festejar la derrota alemana y la firma del Tratado de Versalles-, se realizó el 14 de julio de 1919 un imponente desfile militar en París, con la consagración del 11 de noviembre como fecha de recuerdo oficial del cese de las hostilidades en el frente occidental. ${ }^{13}$

Las elecciones políticas del 16 de noviembre de 1919, arrojaron resultados decepcionantes para liberales y nacionalistas, en tanto que socialistas y católicos del Partito Popolare obtuvieron un éxito resonante. Esto fue interpretado como una confirmación de la orientación pacifista de vastos sectores de la ciudadanía. ${ }^{14}$

11. Sobre el antimilitarismo de izquierda, ver: ROCHAT, Giorgio, L'esercito italiano in pace e in guerra. Studi di storia militare, Rara, Milano, 1991, pp. 145-177; y BIANCHI, Roberto, Pane, pace, terra, Il 1919 in Italia, Odradek, Roma, 2006.

12. MONDINI, Marco, "La festa mancata. I militari e la memoria della Grande Guerra (1918-1923)", en Contemporanea, Bologna, 2004, № 4, pp. 555-579.

13. MINIERO, Alessandro, Da Versailles al Milite Ignoto. Rituali e retoriche della Vittoria in Europa (1919-1921), Istituto per la Storia del Risorgimento Italiano, Roma, 2008.

14. BARAVELLI, Andrea, "Guerra, politica ed emozioni: l'uso del ricordo della guerra in occasione delle elezioni politiche nel novembre 1919 (i casi di Francia e Italia)", en Ricerche di storia politica, Bologna, 2001, № 3, pp.
Los desgarramientos y disputas al interior de la sociedad italiana como producto de la Gran Guerra, se evidencian, a su vez, en el recuerdo público de ésta. Así, en los monumentos erigidos en cada comuna del país, comparecen los nombres de los conciudadanos caídos, transformando las plazas principales en lugares de expresión del culto póstumo de la guerra. ${ }^{15}$ Dicho proceso ocurre asimismo, en otros países europeos participantes de la conflagración mundial. $^{16}$

Muchos de estos monumentos trasmiten una visión de la muerte como resultado trascendente del cumplimiento del deber. Este concepto aparece sintetizado en dos inscripciones omnipresentes: el verso de Horacio (Odas III, $2,13)$ Dulce et decorum est pro Patria mori, y las frases Chi per la Patria muor / vissuto è assai de la canción Chi per la Patria muor (1828), de Paolo Pola, que integra el repertorio de canciones patrióticas de la era del Risorgimento.

De acuerdo a las alternativas de los equilibrios políticos locales, se enfrentaron dos memorias en pugna: por un lado, una primera memoria donde preponderaban elementos de corte

311-340.

15. CANAL, Claudio, "La retórica della morte. I monumenti ai caduti della Grande Guerra”, en Rivista di storia contemporanea, 1982, No 4, pp. 659-669; MONTELEONE, Renato y SARASINI, Pino, "I monumenti italiani ai caduti della Grande Guerra", en LEONI, Diego y ZADRA, Camillo (compiladores) La Grande Guerra. Esperienze, memoria, immagini, il Mulino, Bologna, 1986, pp. 631-662.

16. BECKER, Annette, Les monuments aux morts, mémoire de la Grande Guerre, Errance, Paris, 1988; KING, Alex, Memorials of the Great War in Britain. The Symbolism and Politics of Remembrance, Berg, Oxford, 1998; WINTER, Jay, Sites of Memory, sites of mourning. The Great War in European Cultural History, Cambridge University Press, Cambridge, 1995. 
belicista-nacionalista, y por otro, su opuesta, caracterizada por una definición de tipo pacifista-internacionalista. A esto siguió la consideración disputada de los caídos en tanto que héroes conscientes de su inmolación por la patria, o en sentido opuesto, como víctimas de las estrategias urdidas por las elites político-militares. En torno a los monumentos se produjeron, de esta suerte, frecuentes enfrentamientos físicos que provocaron un sinnúmero de heridos y muertos.

Durante el denominado "bienio rojo", entre 1919 y 1920, predominó la aversión a la guerra, a consecuencia del trauma subsistente y del duelo aún no elaborado, producto de la tragedia sufrida. En este período, el socialismo se mantuvo a la ofensiva y la sociedad en su conjunto -en vistas del proceso ruso-, parecía transcurrir a la espera del inminente estallido revolucionario. De hecho, en 1919 se propuso, incluso, la abolición del ejército y el desarme general, así como la inserción de Italia en el marco de las repúblicas proletarias ligadas a la Komintern. En realidad, a pesar de apariencias y proclamas ideológicas, el Partido Socialista no lograría hacerse con el poder: la ocupación de las fábricas organizada en el verano europeo de 1920 en Turín, constituyó el canto del cisne de las izquierdas a nivel social y sindical, agotándose en medio de un elocuente aislamiento. De hecho, a inicios de ese mismo año, los movimientos obrero y campesino ya se encontraban a la defensiva, en tanto que empresarios y terratenientes sostenían financieramente al fascismo, autoproclamado como defensor del país frente al "enemigo interno", a saber, socialistas, comunistas y anarquistas.

Aquellos monumentos que atribuían los desastres de la guerra al militarismo, resultaron dañados o destruidos por squadristi o removi- dos por las autoridades de derecha instaladas luego de la marcia su Roma y del inicio del gobierno de Mussolini. Como señala Mario Isnenghi, se produjo entonces una "segunda oleada monumental", ${ }^{17}$ aún más intensa que aquella desarrollada a posteriori del proceso de unificación nacional, que había poblado el país de monumentos y lápidas dedicadas a Giuseppe Garibaldi. Puede pensarse este fenómeno, ideado por las autoridades en el marco de las políticas de reafirmación identitaria, como una instrumentalización del reclamo de los familiares por las muertes generadas en la guerra, una estrategia que apuntaba a la elaboración pública del duelo privado.

\section{La invención del Milite Ignoto (1921)}

La Gran Guerra provocó la muerte de cerca de 10 millones de soldados ${ }^{18}$ en Italia la cifra ascendió a 578.000-, muchos de los cuales fueron literalmente desintegrados en el campo de batalla (destrozados en los combates a consecuencia de los efectos de las nuevas tecnologías bélicas utilizadas), y declarados desaparecidos. Una tragedia colectiva de dimensiones inéditas, sobre la cual se inscribió, en base a una serie de iniciativas gubernamentales, el mito de los caídos. ${ }^{19}$

17. ISNENGHI, Mario, Le guerre degli Italiani. Parole, immagini, ricordi 1848-1945, il Mulino, Bologna, 2005, p. 342 .

18. STEVENSON, David, 1914-1918 Historia de la Primera Guerra Mundial, Debate, Buenos Aires, 2014, p. 700 .

19. MOSSE, George L., Soldados caídos. La transformación de la memoria de las guerras mundiales, Prensas de la Universidad de Zaragoza, Zaragoza, 2016. 
La idea de honrar la memoria de los militares "desaparecidos" se concretó en 1920 en Francia, y en Gran Bretaña. En el año siguiente se extendió a Italia, Bélgica, Portugal y Estados Unidos..$^{20} \mathrm{El}$ imponente ritual organizado por las autoridades como respuesta institucional a la conmoción social determinada por el elevado número de caídos, logró incorporar a la población en la conmemoración planificada de un ceremonial colectivo de la muerte, que apelaba a la inclusión conmovida/comprometida de la sociedad en el marco de la consolidación de una "religiosidad" laico-patriótica de "nacionalización de las masas". ${ }^{21}$

En Italia, el proyecto del Soldado Desconocido fue propuesto en julio de 1920 por el coronel Giulio Dohuet, para honrar a los desaparecidos o dispersi, colocando el ataúd de un combatiente desconocido -símbolo del ciudadano-soldado obediente a la Patria hasta el sacrificio extremo-, en el Altare della Patria (monumento conocido como il Vittoriano, dedicado al Risorgimento y a la dinastía Saboya) en la capital del país, bajo la escultura dedicada a la Diosa Roma. ${ }^{22}$

Por amplia mayoría, el parlamento del Reino aprobó el 4 de agosto de 1921 la ley que definió el 4 de noviembre como Festa della Vittoria. Mientras los dos precedentes aniversarios del fin de la guerra estuvieron signados por recordaciones desarrolladas en un registro amor-

20. Véase una mirada comparativa en: MINIERO, Alessandro, Da Versailles..., Op. Cit.

21. VOVELLE, Michel, La mort et l'Occident de 1300 à nos jours, Galllimard, Paris, 1983; MOSSE, George L., The Nationalization of the Masses. Political Symbolism and Mass Movements in Germany from the Napoleonic Wars through the Third Reich, Howard Fertig, New York, 1975.

22. TOBIA, Bruno, L'Altare della Patria, il Mulino, Bologna, 1998.

90 tiguado, -superadas por las movilizaciones internacionalistas y antimilitaristas que se desarrollaron en la misma coyuntura-, a partir de 1921 la situación se modificó profundamente. De todas formas, las autoridades organizaron el despliegue preventivo de un aguerrido aparato de control del orden público, con más de 16.000 efectivos entre carabinieri, guardias reales y divisiones del ejército. ${ }^{23}$

El féretro, albergando los restos del Soldado Desconocido y cubierto por la bandera italiana, fue elegido por la madre de un soldado desconocido caído en combate, entre otros once militares, cuyos despojos mortales habían sido recuperados en varios sectores del frente de batalla. La ceremonia, dirigida por la Commissione nazionale per le Onoranze ai caduti in guerra, se realizó el 28 de octubre de 1921 en la antigua Basilica di Santa Maria Assunta, en la localidad de Aquileia, sobre la frontera oriental del país. ${ }^{24}$

Con un excepcional esfuerzo organizativo y un sugestivo montaje, el transporte del $\mathrm{Mi}$ lite Ignoto, se inició en el norte de Italia para arribar a la capital en un tren embanderado y escoltado por veteranos de guerra, mutilados $\mathrm{y}$ ataviados con medallas de honor al valor. Por una semana, el convoy recorrió a velocidad reducida la línea Aquileia-Venecia-Bolo-

23. MONDINI, Marco y SCHWARZ, Guri, Dalla guerra alla pace. Retoriche e pratiche della smobilitazione nell'Italia del Novecento, Cierre Edizioni, Vicenza, 2007, p. 113.

24. Sobre las ceremonias de octubre-noviembre de 1921, véase: LABITA, Vito, "Il Milite Ignoto. Dalle trincee all'Altare della Patria”, en BERTELLI Sergio y GROTTANELLI, Cristiano (compiladores) Gli occhi di Alessandro. Potere sovrano e sacralità del corpo da Alessandro Magno a Ceaucescu, Ponte alle Grazie, Firenze, 1990, pp. 120-153; CADEDDU, Lorenzo, La leggenda del soldato sconosciuto all'Altare della Patria, Gaspari, Udine, 2001. 
nia-Florencia-Roma, con paradas en innumerables estaciones para recibir el homenaje de la población. Gracias a una monumental propaganda, acudieron cientos de miles de ciudadanos, que al paso del tren expresaron su congoja en una suerte de manifestación de religiosidad patriótica. Con solemnidad, el féretro es inhumado en un sarcófago en la plaza del Altare della Patria el 4 de noviembre, ubicándosele en una posición más elevada respecto de la Piazza Venezia, para asegurar así una máxima visibilidad. En la ocasión, los restos mortales del Soldado Desconocido, fueron honrados con la mayor condecoración al valor:

Degno figlio di una stirpe prode e di una millenaria civiltà, resistette inflessibile nelle trincee più contese, prodigò il suo coraggio nelle più cruente battaglie e cadde combattendo senz'altro premio sperare che la vittoria e la grandezza della Patria. ${ }^{25}$

Benito Mussolini otorgó particular atención a la creación de la figura del Soldado Desconocido. En 1914, se apartó del Partido Socialista, defendiendo la intervención de Italia en la guerra. Se enroló finalmente en 1915, resultando poco después herido en un ejercicio de combate. Una vez finalizada la conflagración mundial, fundó en Milán, el 23 de marzo de 1919, los fasci di combatimento, cuyo programa político valorizaba la experiencia bélica. A fines de octubre de 1921, cuando las ceremonias vinculadas al Milite Ignoto movilizaron a amplios sectores de la población, Mussolini, en vísperas de la transformación del fascismo de

25. TOGNASSO, Augusto, Ignoto Militi, Zanoli, Milano, 1922. "Digno hijo de una estirpe intrépida y de una civilización milenaria, resistió inflexible en las trincheras más disputadas, prodigó su valentía en las más cruentas batallas y cayó combatiendo sin esperar más premio que la victoria y la grandeza de la Patria" (traducción propia). movimiento en partido -ocurrida en el congreso realizado en Roma, entre el 7 y el 10 de noviembre de 1921-, observó que la política italiana se encontraba en un momento clave y el fascismo debía prepararse para la toma del poder, en virtud de la incapacidad característica de los gobiernos liberales para neutralizar a la izquierda política:

Le cerimonie di questi giorni rappresentano un momento importantissimo nella storia della nazione. Sono l'indice di una psicologia cambiata. Hanno rivelato l'anima vera, profonda e pura, del popolo italiano. Il Governo sa che ora, volendo, può schiantare le forze dell'antinazione. Se non lo fa, ci penseremo noi. ${ }^{26}$

Momentos antes del congreso fundacional del Partito Nazionale Fascista, Mussolini reivindicó no tanto la paternidad de la iniciativa (propuesta por Douhet, y realizada por el gobierno del socialista reformista Ivanoe Bonomi), sino el impulso proporcionado por la mutación del clima político en Italia, en plena deriva nacionalista: "Sin el fascismo, el Soldado desconocido hoy no dormiría en el sarcófago del Altare della Patria". ${ }^{27}$ El 8 de noviembre, en el mensaje al congreso mencionado, preanunció su programa político: "Nosotros, por la Nación, aceptamos la dictadura y el estado de sitio". ${ }^{28}$

26. MUSSOLINI, Benito, "Popolo", en il Popolo d'Italia, 5 noviembre 1919, en MUSSOLINI, Benito, Opera Omnia di Benito Mussolini, V. XVII, La Fenice, Firenze, 1955, pp. 209-210. "Las ceremonias de estos días representan un momento importantísimo en la historia de la nación. Son la expresión de una psicología diferente. Revelan el alma verdadera, profunda y pura, del pueblo italiano. El Gobierno ahora sabe que, si así lo quiere, puede destrozar a las fuerzas de la anti-nación. Si no lo hace, lo haremos nosotros". (Traducción propia).

27. Ídem, p. 219.

28. Un sugerente contraste entre el cuerpo del soldado 
El Milite Ignoto, -ejemplo significativo del uso político de la muerte en el campo de batalla-, constituye un elemento medular en la transformación de la política italiana que se produjo en este período, con el fortalecimiento de las tendencias ideológicas nacionalistas, artífices y beneficiarias de la construcción de un sentido de cohesión patriótica que imperaría durante el ventennio fascista. Socialistas y comunistas fueron desplazados de esta ceremonia de masas. Su interpretación de la guerra como una "carnicería" de la cual los soldados-víctimas fueron obligados a participar, aniquilándose contra su voluntad para satisfacer el mandato del capitalismo hegemónico, resultó relegada en tanto que minoritaria.

De este modo, el recuerdo de la guerra que prevaleció, como parte de las políticas oficiales de la memoria de la postguerra, se expresó en lo que George Mosse ${ }^{29}$ denomina como "mito de la experiencia de guerra", a partir del cual la guerra se transforma en "experiencia sagrada" y el culto al soldado caído en "clave de bóveda de la religión del nacionalismo" desarrollada en los años posteriores al conflicto.

\section{I1 Sacrario Militare di Redipuglia (1935-1938)}

Durante el régimen mussoliniano, se ideó el ambicioso proyecto de concentrar en una única localidad, los restos mortales de decenas de miles de soldados, en el marco de una dimensión patriótico-religiosa que exaltó las poten-

desconocido y el de Mussolini, figura en: POZZI,

Enrico, "Il Duce e il Milite ignoto: dialettica di due corpi politici”, en Rassegna italiana di Sociologia, Bologna, 1998, No 3, pp. 333-358.

29. MOSSE, George L, Soldados caídos..., Op. Cit., p. 35. 92 cialidades nacionalistas y belicistas del fascismo, atendiendo a la perspectiva de que nuevas guerras permitiesen acrecentar la grandeza de la patria. La política de memoria desarrollada a partir de la construcción de la figura del Soldado Desconocido, ${ }^{30}$ impulsó en los años veinte la construcción de grandes cementerios y monumentos-osarios en decenas de localidades donde se habían producido combates. ${ }^{31}$ A la muerte en masa en los campos de batalla de la Gran Guerra, correspondería, de esta forma, la construcción de enormes tumbas colectivas, diseñadas por la dictadura fascista para conmemorar la experiencia de la muerte en combate como parte de una estrategia político-pedagógica de potenciar valores de corte nacionalista a través del recuerdo colectivo de los combatientes en tanto héroes anónimos de la patria. El régimen fascista, en tanto que emprendedor de memoria, ${ }^{32}$ operó la tarea de consolidar una memoria única sobre la guerra, sacralizada a partir de la construcción de espacios de rememoración que otorgaron a esta muerte anónima un valor heroico, recubriendo de honor la muerte no honorable de la Gran Guerra, al decir del historiador Enzo Traverso, la muerte "en el matadero". ${ }^{33}$

30. TOBIA, Bruno, "Dal Milite ignoto al nazionalismo monumentale fascista", en BARBERIS, Walter (compilador) Storia d'Italia. Annali 18. Guerra e pace, Einaudi, Torino, 2002, pp. 593-642.

31. En la obra de Lisa Bregantin, figuran fichas de los principales cementerios de guerra italianos. BREGANTIN, Lisa, Per non morire mai..., Op. Cit., pp. 254-261.

32. Véase al respecto de este concepto en: JELIN, Elizabeth Los trabajos de la memoria, Siglo XXI, Madrid, 2002.

33. TRAVERSO, Enzo, A sangre y fuego. De la guerra civil europea, 1914-1945, Prometeo, Buenos Aires, 2009, pp. 166-167. George L. Mosse reflexiona, en esta dirección, sobre el uso de elementos decorativos en memoriales alemanes de la guerra, donde puede observarse la 
La localidad elegida para erigir el mayor mausoleo nacional, fue Redipuglia, en Friuli-Venezia Giulia, entre las ciudades de Udine y Monfalcone y cerca del límite oriental del país. En dicha zona se produjeron -desde el 23 de junio de 1915 al 7 de noviembre de 1917-, doce sangrientas batallas.

En Redipuglia se inhumaron 100.187 soldados caídos, de los cuales 39.857 reconocidos y 60.330 desconocidos, provenientes de todos los frentes de guerra en Italia. El arquitecto Giovanni Greppi y el escultor Giannino Castiglioni, proyectaron una opera di solidissima struttura ispirata all'idea di un formidabile $e$ ordinato schieramento militare con alla testa $i$ comandanti. ${ }^{34}$

Una enorme escalinata de veintidós gradas de mármol, vertebra el monumento. Cada grada reproduce la palabra "presente", en relieve, repetida al infinito como forma de conmemorar la presencia de los militares muertos, y su solemne rememoración, adquiere a través de la presencia de tres grandes cruces en la terraza superior, un sentido religioso: lo sviluppo ascensionale e le tre Croci che lo concludono, associano alla solennità del monumento il chiaro significato mistico della redenzione al di là della vita terrena: le anime dei Caduti che salgono al cielo. ${ }^{35}$ Resulta

ocultación de toda referencia a armas modernas, y su sustitución por espadas guerreras. "Morir por la espada... era morir por la mano del hombre, y solo una lucha con combates hombre a hombre parecía verdaderamente heroica”. MOSSE, George L, Soldados caídos..., Op. Cit., p. 141.

34. Commissariato Generale Onoranze Caduti in Guerra (compilador) Sacrari Militari della $1^{a}$ Guerra Mondiale. Redipuglia, Ministero della Difesa, Roma, 1984, p. 7. "Obra de muy sólida estructura, inspirada en la idea de una formidable y ordenada alineación militar con sus comandantes a la cabeza”. (Traducción propia).

35. Ibídem. "El trayecto ascensional y las tres Cruces relevante el peso de los elementos religiosos en el Sacrario. La cripta con las imágenes del viacrucis, complementan el carácter sacro del memorial, coronado por las tres enormes cruces mencionadas. Este sentido religioso, junto a los elementos arquitectónicos y decorativos de orden clásico dota al mausoleo de un carácter de inmutabilidad, que habilita la expresión solemne del culto cívico nacional sostenido por el nacionalismo extremo.

En el centro de la gran plaza, luego del primer descanso de la escalinata, se ubica una lápida cuya leyenda, de contenido marcadamente fascista, declara:

O MORTI GLORIOSI D'ITALIA / DA QUESTO
CIMITERO DEGLI INVITTI / CHE È SINTESI
IMMORTALE DEI SACRIFICI E DELLA GLORIA
DELLA PATRIA / EMANA UNA LUCE COME
Di BALENO / CHE SARÀ IL FARO D'ITALIA. ${ }^{36}$

Faro de Italia, para iluminar el futuro belicista pergeñado por el régimen, centralizando y sacralizando "con fuerza la memoria oficial de una guerra y de un pueblo victorioso" en el momento en el cual "el Estado fascista, ya comprometido en las guerras de África y España, en poco más impondría a la población una nueva guerra y pesados sacrificios ulteriores en nombre de los destinos imperiales de la nación". ${ }^{37}$

(sic) que lo concluyen, asocian a la solemnidad del monumento el claro significado místico de la redención más allá de la vida terrena: Las almas de los Caídos (sic) que se elevan al cielo" (Traducción propia).

36. Ídem, p. 11. "Oh muertos gloriosos de Italia/ De este cementerio de los invictos/ Que es síntesis inmortal de los sacrificios y de la gloria de la Patria/ Emana una luz como de relámpago/ Que será el faro de Italia" (Traducción propia).

37. FABI, Lucio, "Territorio e memoria. Il fronte italoaustriaco", en GIBELLI, Antonio (editor) La prima 


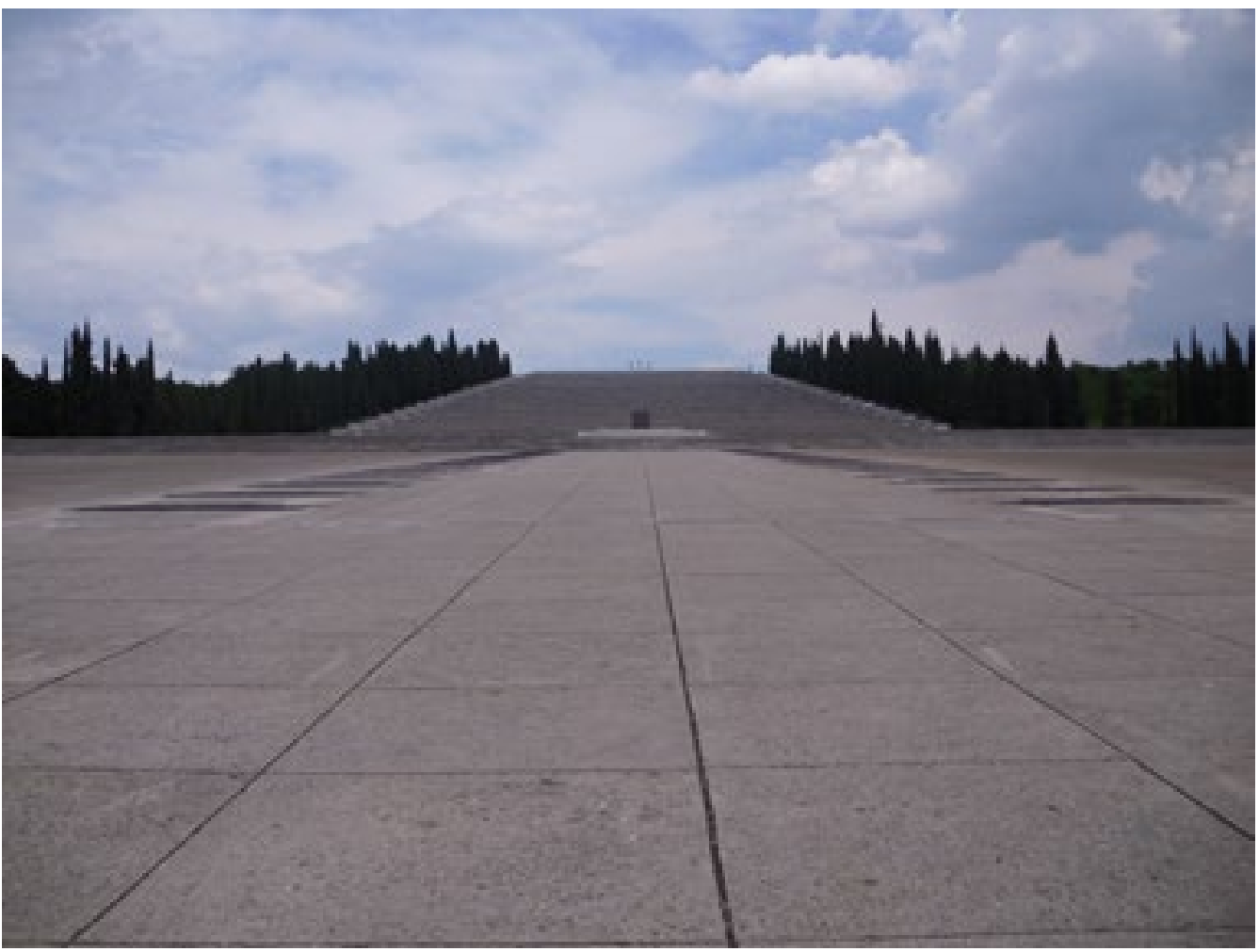

Fotografía 1 - "Sacrario Militare di Redipuglia (I)" - Autora: Marina Cardozo

En Redipuglia confluyen peregrinajes colectivos de veteranos, parientes y familiares de los caídos, estudiantes, inscriptos en asociaciones militares, turistas. ${ }^{38}$ Impactante por su imponencia, por el efecto sobrecogedor y teatral que busca ejercer sobre el espectador, este cementerio militar es considerado por los estudios sobre memoria existentes como el lugar "más importante, reconocido y conocido a nivel

guerra mondiale, V. II, Einaudi, Torino, 2007, pp. 530-531. (Traducción propia).

38. FABI, Lucio, Redipuglia. Il Sacrario, la guerra, la comunità, Editorial della Laguna, Monfalcone, 1993. nacional e internacional, así como el más frecuentado". 39

Después de la caída de la dictadura, el significado del Sacrario se extendió simbólicamente a los caídos italianos de todas las guerras (incluidas, por ende, las guerras generadas por el régimen fascista, como la de Etiopía, o la intervención italiana en la Guerra Civil Española, y las agresiones a varios países en el marco de

39. DOGLIANI, Patrizia, "Redipuglia”, en ISNENGHI, Mario (compilador) I luoghi della memoria. Simboli e miti dell'Italia unita, Laterza, Roma-Bari, 1996, p. 377. 


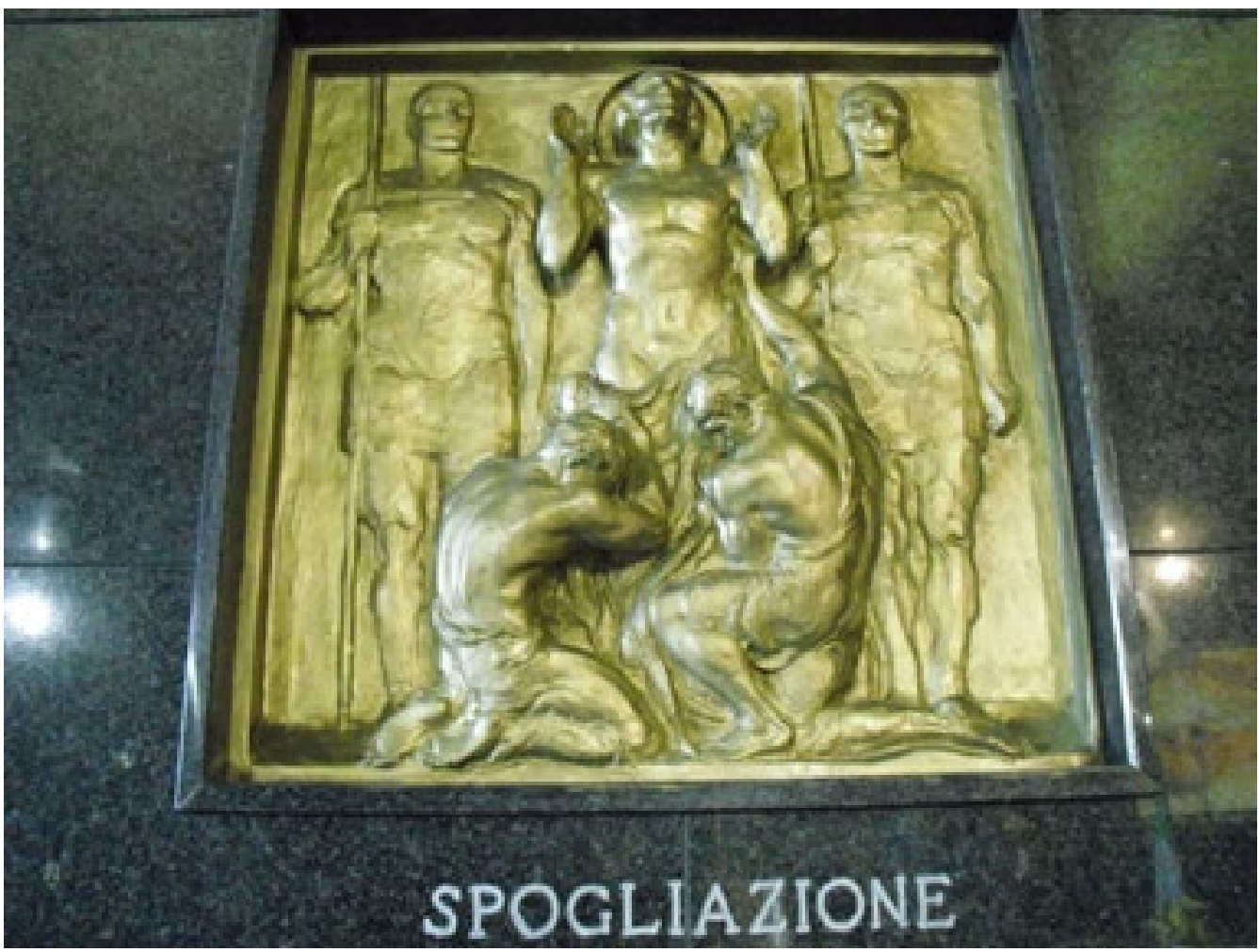

Fotografia 2 - "Sacrario Militare di Redipuglia (II)" - Autora: Marina Cardozo

la Segunda Guerra Mundial). ${ }^{40}$ Ello silenció el valor particular que el fascismo había atribuido a este lugar de memoria, y que sin embargo permanecieron en la forma de marcas monumentales ignoradas oficialmente, aunque existentes. Aun cuando fueron eliminados algunos de los elementos simbólicos principales del fascismo, representados en diversas partes del memorial, como los fasci littori, otras muchas

40. FOCARDI, Filippo y KLINKHAMMER, Lutz, "La rimozione dei crimini di guerra dell'Italia fascista. La nascita di un mito auto assolutorio", en GOGLIA, Luigi (compilador) Guerra e pace nell'Italia del Novecento, il Mulino, Bologna, 2006, pp. 251-290. huellas del régimen presentes en el cementerio, perduraron incólumes.

En ocasiones particularmente solemnes, se han realizado en Redipuglia ceremonias con la presencia de presidentes de la República, como por ejemplo, el 4 de noviembre de 1968, -en el cincuentenario del armisticio ítalo-austríaco-, cuando visitó el monumento el socialdemócrata Giuseppe Saragat, (exiliado antifascista durante la dictadura), o bien, una década más tarde, el socialista Sandro Pertini, condecorado al valor por su actuación en la Gran Guerra. 
El Sacrario revela la presencia de importantes elementos decorativos fascistas. Dos de los más significativos, ignorados por las visitas guiadas al cementerio, son, dentro de la cripta, un bajorrelieve del Via Crucis, en el cual aparece a la izquierda la figura de Mussolini, ataviado como soldado romano.

A la salida de la cripta, se tropieza con la lápida colocada al momento de la inauguración de la obra:

\begin{abstract}
REGNANDO VITTORIO EMANUELE III / CAPO SUPREMO DELLA GUERRA VITTORIOSA BENITO MUSSOLINI DUCE D'ITALIA E FONDATORE DELL'IMPERO / QUESTO SACRARIO DI REDIPUGLIA / CHE ATTORNO AL CONDOTTIERO DELLA TERZA ARMATA RACCOGLIE CENTOMILA CADUTI DELLE DODICI BATTAGLIE CARSICHE / CONSEGNAVA ALLA GLORIA E ALLA RELIGIONE DEGLI ITALIANI / I 3 SETTEMbre I 938 XVI Era Fascista. ${ }^{41}$
\end{abstract}

La presencia de esta lápida resulta indicativa de la conservación en la era democrática, de un número importante de huellas de la dictadura, diseminadas en el paisaje italiano; muchas de ellas han sido redescubiertas y revalorizadas recientemente, ${ }^{42}$ en medio de polémicas de in-

41. "Reinando Vittorio Emanuele III/ Jefe Supremo de la Guerra Victoriosa Benito Mussolini, Duce D'Italia y fundador dell'Imperio/ Este Sacrario de Redipuglia/ Que en torno al Comandante (Duque d'Aosta sepolot a Redipuglia) de la tercera división del ejército recoge cien mil caídos de las doce batallas carsiche / Entregaba a la gloria y a la religión de los italianos/ 13 de setiembre de 1938 XVI Era Fascista”. (Traducción propia).

42. Como ejemplo de lo antedicho, destaca el reciente evento vinculado al Bosco mussoliniano que, instituido en 1939 por la guardia forestal en el Monte Giano (comuna de Antrodoco, Rieti, Lazio), presenta desde su creación una composición conformada por 20.000 pinos, recreando en grandes caracteres la palabra DUX. E1 23 de agosto de 2017 un incendio dañó gravemente la obra. El presidente de la comuna, síndico Alberto Guerrieri telectuales y políticos que no siempre siguen el esquema clásico de derecha/izquierda. Algunos investigadores del campo de estudios sobre la memoria, han reflexionado acerca de las diferentes formas de procesar los pasados autoritarios en Italia y Alemania. ${ }^{43}$ Aunque la solución "normalizadora" del pasado en Alemania con relación a los crímenes del nazismo, produjo un pasado "domesticado", asentado en la cuidadosa elaboración de un "aparato conmemorativo bien aceitado", ${ }^{44}$ en el caso italiano, ocurre un deliberado borramiento, por parte de la memoria institucional, de zonas traumáticas del pasado autoritario, así como un intento de sofocar posibles contra-memorias a la narrativa oficial. Con todo, las disputas sobre estos pasados no producen un cierre definitivo de los debates, ya que se trata de pasados no cerrados, sino en continua reinterpretación. ${ }^{45}$

Las publicaciones oficiales sobre Redipuglia seleccionan atentamente qué recordar, omiten aquello a olvidar, buscan establecer una memoria. Enfatizan los actos heroicos, e ignoran cualquier episodio revelador de contradiccio-

sostuvo en la ocasión: "Me siento destruido. Una parte importante de nuestra identidad se ha evaporado con el humo". En tanto, el movimiento neofascista Casa Pound, anunció la reconstrucción del bosque. Disponible en: <https://www.ilfattoquotidiano.it/2017/08/25/ incendi-brucia-la-scritta-dux-sul-monte-giano-ilsindaco-di-antrodoco-in-fumo-un-pezzo-della-nostraidentita/3816289/>.

43. FOCARDI, Filippo, "Il vizio del confronto. L'immagine del fascismo e del nazismo in Italia e la difficoltà di fare i conti con il proprio passato", en RUSCONI, Gian Enrico y WOLLER, Hans (compiladores) Italia e Germania 1945-2000. La costruzione dell'Europa, il Mulino, Bologna, 2005, pp. 91-124.

44. JELIN, Elizabeth, La lucha por el pasado...,Op. Cit., pp. 34-38.

45. Ibídem. 


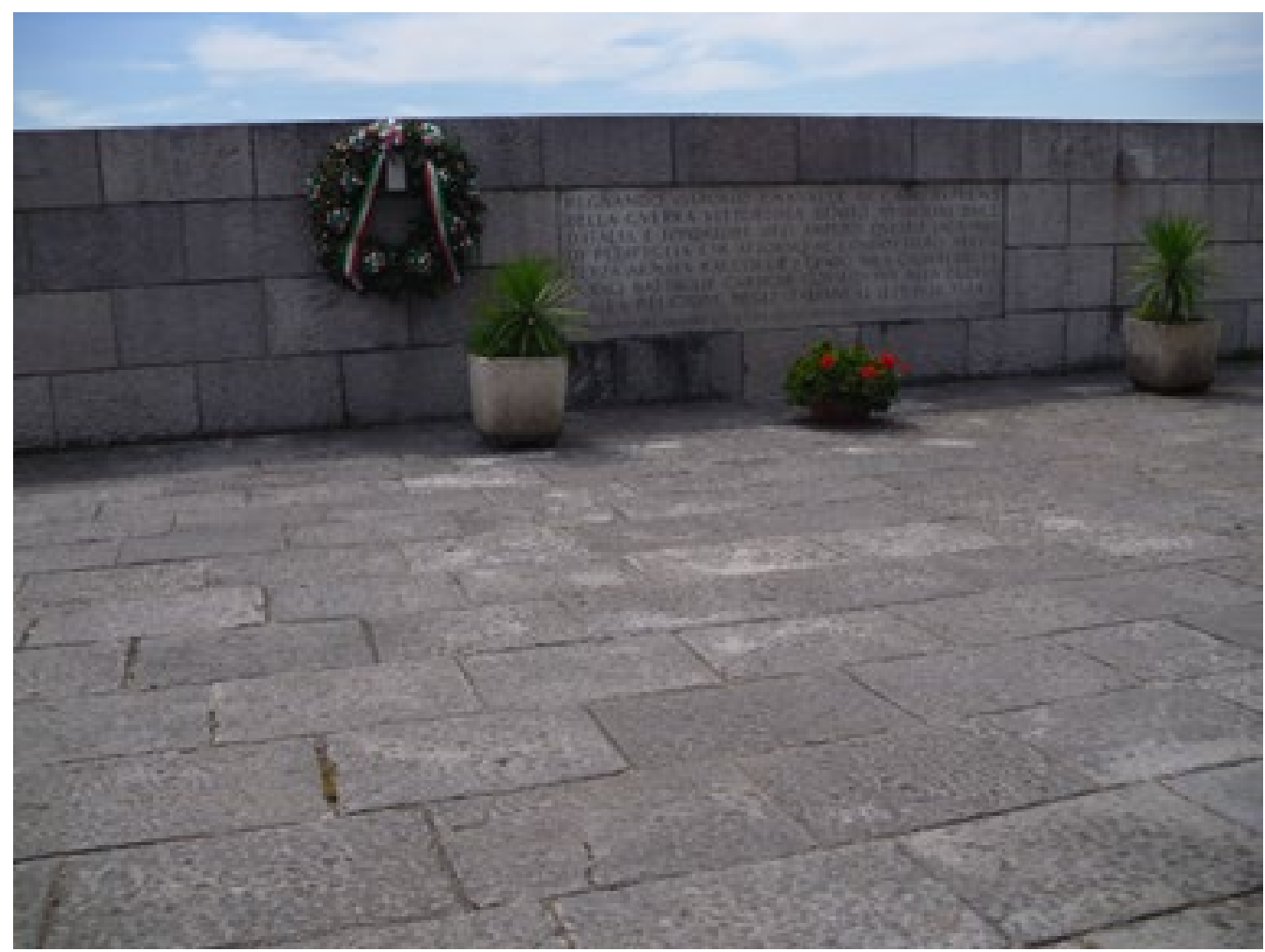

Fotografía 3 - "Sacrario militare di Redipuglia (III)" - Autora: Marina Cardozo

nes en torno a la guerra. Censuran por ejemplo, el motín ocurrido el 15 de julio de 1917 en los alrededores de Redipuglia, por parte de 150 soldados de la Brigada Catanzaro a quienes, habiéndoseles concedido un período de descanso después de atravesar duros combates, se rehusaron a retornar al frente de guerra, y dispararon sus armas contra oficiales y carabinieri que buscaban prenderlos a los efectos de obligarlos a retornar a las líneas de combate. Este episodio subversivo fue sofocado con el saldo de veintiocho soldados fusilados sin proceso, combinando la decimazione, (instrumento derivado del código penal militar italiano de
1870, consistente en fusilar -en una división rebelde-, a un soldado de cada diez, según la posición ocupada en una fila) y el sorteo de nombres, para determinar las condenas a muerte. ${ }^{46}$ Los veintiocho soldados ejecutados fueron sepultados en una fosa común. No se encuentran en el Sacrario, principal cementerio militar en el país, en el cual no existe ningún tipo de indicio de la rebelión más grave ocurrida en el ejército italiano durante la Primera Guerra Mundial.

46. PLUVIANO, Marco y GUERRINI, Irene, $L e$ fucilazioni sommarie nella prima guerra mondiale, Gaspari, Udine, 2004, pp. 70-75. 


\section{La memoria contradictoria de la República}

Una vez producido el derrumbe del fascismo, el advenimiento de la democracia atenuaría la importancia de la Gran Guerra como factor identitario de la nación italiana. Ello ocurrió entre otros elementos, porque además del surgimiento de la Resistencia como nuevo elemento de cohesión nacional (aunque parcial y disputado), ${ }^{47}$ la destrucción provocada por la Segunda Guerra Mundial colocó en una perspectiva diversa a la Gran Guerra: como el preludio de una masacre aún mucho más terrible que la acaecida entre 1914 y 1918 (en Italia morirán durante el segundo conflicto mundial, 320.000 militares y partisanos, y $153.000 \mathrm{ci}^{-}$ viles).

En su estudio de la retórica de los mensajes republicanos del 4 de noviembre a las fuerzas armadas, desde 1945 a nuestros días, el historiador Nicola Labanca indica una menor centralidad del énfasis nacionalista y militarista (elementos que teñían la conmemoración durante el período dictatorial), a la vez que, sin embargo, la pervivencia en estos discursos de un sentido patriótico, todo ello enmarcado en un progresivo distanciamiento del tema de la Gran Guerra y del recuerdo de ésta. Así, en los mensajes del 4 de noviembre posteriores a la desaparición de la URSS, Labanca releva la creciente preponderancia de referencias a la actualidad política por sobre aquellos aspectos históricos vinculados a la Gran Guerra; a su juicio, los mensajes presidenciales dirigidos a las fuerzas armadas, son sustancialmente au-

47. FOCARDI, Filippo, La guerra della memoria. La Resistenza nel dibattito politico italiano dal 1945 ad oggi, Laterza, Roma-Bari, 2005.

98 torreferenciales y "fotografían mucho más la cultura y los programas de la clase política, que los sentimientos de la sociedad italiana". ${ }^{48}$

A su vez, en torno a las fechas conmemorativas, que al decir de Elizabeth Jelin ${ }^{49}$ constituyen "puntos de entrada privilegiados para el análisis de la tensión entre los rituales que se reiteran y reflejan continuidades identitarias y de sentido, por un lado, y las fracturas, los cambios y transformaciones en las prácticas y significados de las conmemoraciones, por el otro", puede decirse que las fechas-símbolo del 24 de mayo de 1915 y del 4 de noviembre de 1918, declaradas festivas durante el fascismo y celebradas con manifestaciones y discursos nacionalistas, fueron redimensionadas en la era republicana.

Fue descartada rápidamente la rememoración del aniversario de la entrada de Italia en la guerra; entonces la conmemoración del evento bélico se concentró sobre el 4 de noviembre, única ocasión festiva heredada del Estado liberal.

En 1949, en plena guerra fría, la Festa della Vittoria, fue transformada en Giornata delle Forze Armate y celebrada cada año por el presidente de la República con un mensaje a las Fuerzas Armadas, la colocación de una corona de laurel $\mathrm{y}$ un discurso de circunstancia sobre la tumba del Milite Ignoto.

48. LABANCA, Nicola, "Una storia immobile? Messaggi alle forze armate italiane per il 4 novembre (1945-2000)", en Quaderni Forum, Firenze, 2000, Anno XIV, No 3-4, p. 99. (Traducción propia).

49. JELIN, Elizabeth (compiladora) Las conmemoraciones: las disputas en las fechas "in-felices", Siglo XXI, Madrid, 2002, p. 2. 
En tanto, en un clima general de olvido de la Gran Guerra, el 5 marzo de 1977, se determinó por ley que algunos feriados nacionales, entre los cuales el 4 de noviembre, se transformasen en feriados laborables, lo que atenuó o debilitó el sentido simbólico de estas fechas. De todas formas, con el transcurso del tiempo, el 4 de noviembre se conmemorará casi exclusivamente en el ámbito militar.

El mito de la Primera Guerra Mundial, que había sobrevivido a las críticas de la historiografía radical y al paso de las décadas, pervive hoy -gracias al largo aniversario del centenario- en el imaginario colectivo, en un clima de nostalgia alimentado por intelectuales y prensa de derecha, que proponen la recuperación de las dos fechas simbólicas de la guerra. ${ }^{50} \mathrm{El}$ afán conmemorativo, obedece a la búsqueda de perpetuar esa memoria institucional dominante, $y$ radica, a su vez, como expresa Pierre Nora en su conceptualización sobre los lugares de memoria, en la fragilidad de lo que procura proteger dicha memoria: "si lo que defienden no estuviera amenazado, ya no habría necesidad de construirlos. Si los recuerdos que encierran se vivieran verdaderamente, serían inútiles". ${ }^{51}$

En contraste con la nueva centralidad conmemorativa de la Gran Guerra en el presente, resulta manifiesta la ausencia de otras guerras en la memoria de los italianos, como por ejemplo la agresión contra Etiopía en 1935 -donde se utilizaron gases asfixiantes prohibidos por

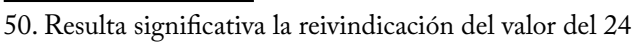
de mayo, por parte del intelectual de derechas Marcello Veneziani, como alternativa al 25 de abril (aniversario de la liberación del nazifascismo). Disponible en: <http:// www.lultimaribattuta.it/26680_veneziani-italia-piave>.

51. NORA, Pierre, Les lieux de mémoire, Montevideo, Trilce, 2008, p. 25. el Protocolo de Ginebra de $1925^{52}$ (Protocolo relativo a la prohibición del empleo en la guerra de gases asfixiantes, tóxicos o similares y de medios bacteriológicos)-, la intervención en España durante la Guerra Civil (1936-1939), la invasión de Albania en 1939, la agresión a Francia en junio 1940, y a Grecia en diciembre de 1940, o el envío de contingentes contra la URSS en $1941 .^{53}$

\section{El Soldado Desconocido en la narrativa de Emilio Franzina.}

Emilio Franzina, destacado contemporaneísta italiano, ha aportado enfoques originales a la historiografía de la guerra desde la perspectiva de la historia social, produciendo una serie de estudios que culminan en la edición del libro Al caleidoscopio della Grande Guerra. Vetrine di donne, di canti e di emigranti 1914-1918. ${ }^{54}$ Franzina sostiene que la Gran Guerra es al mismo tiempo un hecho y un mito potente,

52. Las autoridades políticas y militares italianas negaron durante sesenta años la utilización de gases asfixiantes en Etiopía, hasta que el historiador Angelo Del Boca hizo pública la documentación conteniendo las directivas bélicas de Mussolini al Mariscal Badoglio, respecto del uso del gas en la guerra. DEL BOCA, Angelo, I gas di Mussolini, Il fascismo e la guerra d'Etiopia, Editori Riuniti, Roma, 1996.

53. De estas agresiones militares, se recuerda particularmente la retirada de Rusia en el invierno europeo de 1943. Testimonios e historiografía sobre dicho evento, transforman a los invasores en víctimas de los soviéticos, en una construcción anticomunista propia de los años de la guerra fría. Un ejemplo excepcional de análisis crítico de esta construcción mítica véase en: SCHLEMMER, Thomas, Invasori, non vittime. La campagna italiana di Russia 1941-1943, Laterza, RomaBari, 2009.

54. Al caleidoscopio della grande guerra. Vetrine di donne, di canti e di emigranti 1914-1918, Iannone, Isernia, 2017. 
que representa el evento fundacional clave del siglo XX. ${ }^{55}$ En algunos de sus trabajos se detiene en la reflexión sobre la construcción del Soldado Desconocido, lo que da origen a su novela publicada en 2014, La storia (quasi) vera del Milite Ignoto raccontata come un'autobiografia. ${ }^{56}$ Acerca de la persistencia de este mito, sobreviviente incluso al derrumbe del fascismo (uno de sus principales promotores, como se ha examinado anteriormente), Franzina subraya:

El desastre de la Segunda Guerra Mundial impedía formas vistosas de expresión de los valores militares y nacionalistas, pero el 2 de junio, fiesta de la República, se desarrollaron imponentes desfiles militares. Y en cada Festa della Vittoria, el 4 de noviembre, el Milite Ignoto deviene el centro de las conmemoraciones públicas. Las enormes transformaciones socio-políticas acaecidas desde 1968, hacen perder de vista esta dimensión, alejando de la comprensión de las nuevas generaciones el recuerdo del Milite Ignoto. No obstante hoy, con las crisis económicas recurrentes y la pérdida de puntos de referencia sólidos, emerge nuevamente del pasado, apoyado en la fuerza de los medios de comunicación masivos derivada del aniversario de la Gran Guerra. El riesgo es el de una recuperación errónea, en clave nacionalista. $^{57}$

Especialista en estudios migratorios, Franzina tomó como modelo narrativo en su novela sobre el Soldado Desconocido, la figura real de

55. Entrevista con Emilio Franzina, realizada por Marina Cardozo, Vicenza, Italia, 11/4/2017.

56. FRANZINA, Emilio, La storia (quasi vera) del Milite Ignoto, raccontata come un'autobiografia Donzelli, Roma, 2014.

57. Entrevista con Emilio Franzina, realizada por Marina Cardozo, Vicenza, Italia, 11/4/2017.

100
Américo Orlando, nacido en Brás (San Pablo, Brasil) y llegado a Italia como voluntario de guerra, en 1915. Hasta su muerte, en agosto de 1917, Orlando escribió numerosas cartas a su familia en Brasil, un epistolario conservado por largo tiempo en forma privada y recientemente donado al Archivio Ligure della Scrittura Popolare (Genova), que revela su progresivo desencanto de la guerra y el sufrimiento vinculado a esta experiencia, de la cual inicialmente había participado con sentimiento entusiasta y convicción de justicia.

En la trama de la novela de Emilio Franzina, el personaje central resulta muerto en el frente, como efectivamente sucedió con Orlando (aunque en la narración esto ocurre en 1918), $\mathrm{y}$ es enterrado en un pequeño cementerio local. Exhumado en 1921, será elegido como Soldado Desconocido. Respecto a las conmemoraciones vinculadas al Milite Ignoto, que enfatizan el momento post-mortem, la novela explica los posibles hechos previos, a través de la recreación de la vida de un soldado de los 600.000 caídos, vulnerando la construcción del mito para elaborar una historia verosímil. En cambio, los más de doscientos personajes que rodean la narración novelada de la vida del soldado protagonista, tuvieron existencia real; muchos de ellos fueron líderes políticos del período, o jefes militares, y otros, soldados ignotos de cuya existencia el autor tomó conocimiento a través de la lectura de diarios de guerra y epistolarios populares.

Aun cuando Franzina, en singular experimento literario, escoge no denostar, sino humanizar el recuerdo del Soldado Desconocido a través de su construcción novelada, -relato de la historia de un anti-héroe, soldado anónimo sobre el cual recayeron responsabilidades y riesgos de la guerra-, la novela se transforma 
en una suerte de contra-narración de la figura del Milite Ignoto en tanto que rito nacionalista, figura instrumentalizada para legitimar el catastrófico saldo de la experiencia bélica en una dimensión humana.

\section{Reflexiones finales}

\section{Batallas por la memoria: el monumento al Diser- tore Ignoto}

El recuerdo institucional de la Gran Guerra enfatizó históricamente factores como el patriotismo, el espíritu de sacrificio y la obediencia, censurando aspectos no asimilables a los cánones ideológicos patriótico-nacionalistas imperantes, y exaltando de esa manera las nociones de heroísmo y disciplina de los combatientes. Esta visión se ha sostenido durante largo tiempo, gracias al silencio/olvido de los aspectos no heroicos de la guerra, incluyendo la existencia de varios miles de soldados desertores y/o rebeldes.

Entre 1915 y 1918, hubo al menos 470.000 desertores en el ejército italiano. El número de fusilados fue de 1050, de los cuales 300 fueron ejecutados en forma sumaria, es decir, sin proceso. Se trata de una cifra abultada, si se piensa en los 700 fusilados en Francia -con un ejército que duplicaba el italiano y una participación más prolongada en el conflicto- o bien, en los 306 soldados ejecutados en el ejército británico. ${ }^{58}$ Resulta en ese sentido, un dato indicativo

58. PLUVIANO, Marco, y GUERRINI, Irene, Le fucilazioni sommarie nella prima guerra mondiale, Gaspari, Udine, 2004; DINI, Sergio, PASCULLI, Lorenzo y RIONDATO, Silvio, Fucilazioni e decimazione nel diritto italiano del 1915-1918. Disponible en: <http://www. lorenzopasculli.com/uploads/2/7/3/8/27389245/pascullidini-riondato_fucilazione.pdf >. de la importancia del disenso sobre la experiencia de guerra, así como también de la dura represión ejercida por los comandos militares, especialmente por parte del célebre general Luigi Cadorna.

Sin embargo, tal como ha sido indicado anteriormente, el disenso militar ha sido analizado en forma tardía, sobre todo a partir de la mencionada antología de sentencias de tribunales militares editada en 1968 por Forcella y Monticone.

A su vez, en el ámbito de la memoria pública, no ha encontrado casi eco, si exceptuamos el caso aislado de la iniciativa de un grupo de pacifistas, denominado Gruppo de Azione Nonviolenta, que el 6 de noviembre de 2004, en la Plaza Loreto de la localidad de Rovereto (Trento) inauguró un Monumento al Diserto$r e .^{59}$ Participaron de la ceremonia aproximadamente cien personas, atendiendo asimismo a la ejecución de la balada de Boris Vian Le deserteur, compuesta originalmente en 1954, y traducida al italiano por Ivano Fossati.

El orador de la ceremonia de inauguración, fue el ex partisano Sandro Canestrini, presidente nacional del Movimento Nonviolento, con una larga trayectoria como abogado defensor de los objetores de conciencia al servicio militar, cuando -en ausencia de una ley sobre el servicio civil, aprobada recién en diciembre de 1972-, la objeción de conciencia era penalizada con reclusión carcelaria. ${ }^{60}$

59. $\mathrm{Al}$ respecto de los monumentos sobre desertores en Alemania, véase elensayo de WELCH, Steven R., “Commemorating 'Heroes of a Special Kind': Deserter monuments in Germany, Journal of Contemporary History, 2012, V. 47, No 2, pp. 370-401.

60. CANESTRINI, Sandro, L'ingiustizia militare. Natura e significato dei processi davanti ai giudici in divisa, 


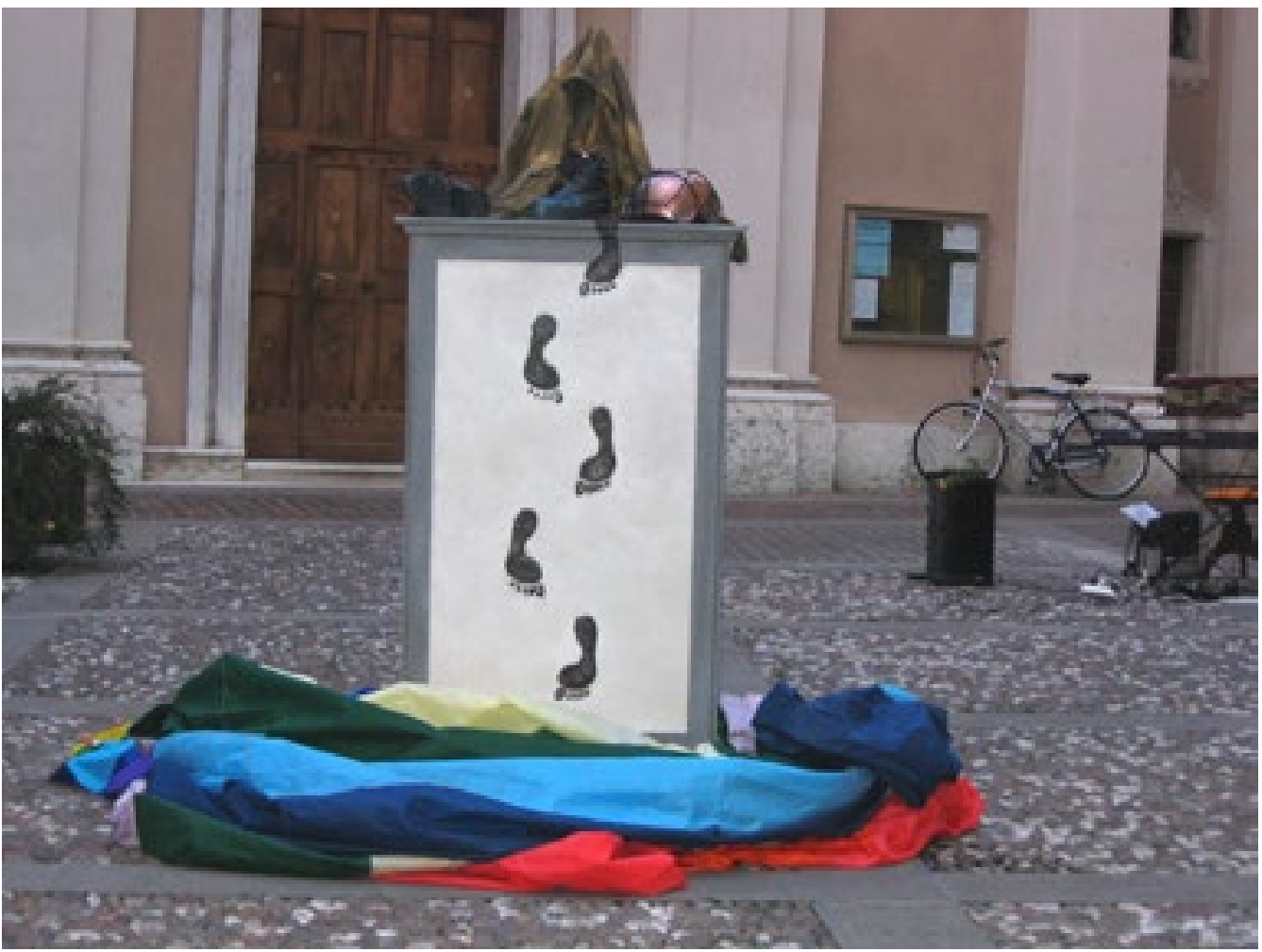

Fotografia 4 - “Monumento al Disertore Ignoto”, Rovereto - Autor: Sandro Canestrini

El monumento presentaba, sobre un basamento de cerca de un metro, un casco, un par de zapatos y un uniforme militar abandonados. En el pedestal aparecen representadas huellas de pies, posiblemente con la intención de expresar la huída de los soldados de una guerra en la que no deseaban combatir. Sobre otra cara del pedestal, una leyenda expresa: Quando lo stato ti insegna ad uccidere si fa chiamare patria. ${ }^{61}$

Feltrinelli, Milano, 1973; y CANESTRINI, Sandro, Un avvocato contro. Tutti gli articoli di Sandro Canestrini, Uomo città territorio, Trento, 2016.

61. "Cuando el Estado te enseña a matar, se hace llamar patria”. (Traducción propia).

102
Pocos días después de inaugurado, el monumento fue removido, no habiéndose concedido por parte de la administración comunal de Rovereto, la autorización para utilizar el espacio ocupado por el monumento en la plaza. Se planteó entonces una fuerte polémica liderada por el movimiento político postfascista Alleanza Nazionale, que presentó un escrito judicial denunciando a Sandro Canestrini y a otros promotores de la iniciativa, en base al artículo 266 del Código Penal, por el delito de instigación a la desobediencia a las autoridades militares. 


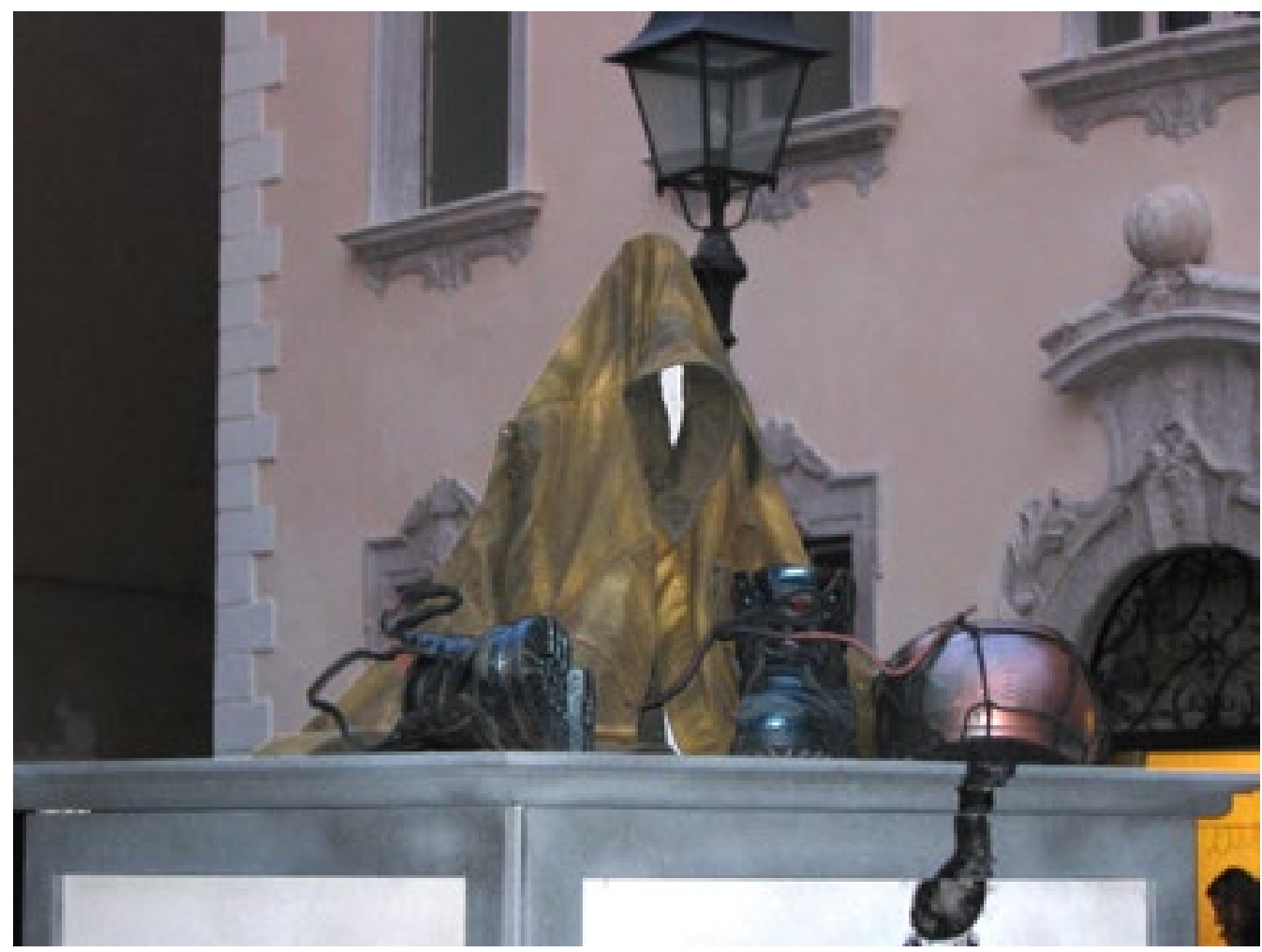

Fotografía 5 - "Monumento al Disertore Ignoto", Rovereto - Autor: Sandro Canestrini

En síntesis, puede decirse que esta memoria subterránea que pone de relieve elementos de disenso respecto de la narrativa institucional y de las políticas oficiales de la memoria sobre la guerra -memoria subterránea y minoritaria que busca arrojar luz sobre determinados aspectos deliberadamente olvidados por la memoria oficial de la guerra-, emerge en coyunturas puntuales vinculadas las fechasaniversario, generando de todos modos, la acérrima oposición de sectores políticos conservadores, que ven en sus iniciativas un intento por desacralizar la elaboración oficial de una política de la memoria en la cual la guerra se constituye en tanto que experiencia heroica y constructora de identidad nacional.<smiles>C=C[Te]=CC</smiles>

Recibido: 01-02-2017 Aceptado: 11-05-2018 Publicado: 07-06-2018 


\section{Bibliografia}

BACZKO, Bronislaw, Los imaginarios sociales. Memorias y esperanzas colectivas, Nueva Visión, Buenos Aires, 1999.

BARAVELLI, Andrea, "Guerra, politica ed emozioni: l'uso del ricordo della guerra in occasione delle elezioni politiche nel novembre 1919 (i casi di Francia e Italia)", en Ricerche di storia politica, Bologna, 2001, No 3, pp. 311-340.

BARBERO, Alessandro, Caporetto, Laterza, Roma-Bari, 2017.

BECKER, Annette, Les monuments aux morts, mémoire de la Grande Guerre, Errance, Paris, 1988.

BIANCHI, Roberto, Pane, pace, terra, Il 1919 in Italia, Odradek, Roma, 2006.

BREGANTIN, Lisa, Per non morire mai. La percezione della morte in guerra e il culto dei caduti nel primo conflitto mondiale, Il Poligrafo, Vicenza, 2010, pp. 254-261.

BURGWYN, H. James, The Legend of Mutilated Victory. Italy, the Great War and the Paris Conference 19151919, Greenwood Press, Westport 1993.

CADEDDU, Lorenzo, La leggenda del soldato sconosciuto all'Altare della Patria, Gaspari, Udine, 2001.

CANAL, Claudio, "La retorica della morte. I monumenti ai caduti della grande guerra", en Rivista di storia contemporanea, 1982, No 4, pp. 659-669.

CANESTRINI Sandro, L'ingiustizia militare. Natura e significato dei processi davanti ai giudici in divisa, Feltrinelli, Milano, 1973.

CANESTRINI Sandro, Un avvocato contro. Tutti gli articoli di Sandro Canestrini, Uomo città territorio, Trento, 2016.

CONNELLY, Mark, The Great War. Memory and Ritual. Commemoration in the City and East London 19161939, Rochester, Boydell, 2002.

DE LUNA, Giovanni, Il corpo del nemico ucciso, Einaudi, Torino, 2006.

DINI, Sergio, PASCULLI, Lorenzo y RIONDATO, Silvio, Fucilazioni e decimazione nel diritto italiano del 1915-1918, Disponible en: <http://www.lorenzopasculli.com/uploads/2/7/3/8/27389245/pascullidini-riondato_fucilazione.pdf >.

DOGLIANI, Patrizia, "Redipuglia”, en ISNENGHI, Mario (compilador) I luoghi della memoria. Simboli e miti dell'Italia unita, Laterza, Roma-Bari, 1996, p. 375-389.

FABI, Lucio, “Territorio e memoria. Il fronte italo-austriaco”, en GIBELLI, Antonio (editor) La prima guerra mondiale, V. II, Einaudi, Torino, 2007, pp. 530-531. 
FERRO, Marc, La Gran Guerra (1914-1918), Alianza, Madrid, 1984.

FOCARDI, Filippo, La guerra della memoria. La Resistenza nel dibattito politico italiano dal 1945 ad oggi, Laterza, Roma-Bari, 2005.

FOCARDI, Filippo, "Il vizio del confronto. L'immagine del fascismo e del nazismo in Italia e la difficoltà di fare i conti con il proprio passato”, en RUSCONI, Gian Enrico y WOLLER, Hans (compiladores) Italia e Germania 1945-2000. La costruzione dell'Europa, il Mulino, Bologna, 2005, pp. 91-124.

FOCARDI, Filippo y KLINKHAMMER, Lutz, "La rimozione dei crimini di guerra dell'Italia fascista. La nascita di un mito auto assolutorio", en GOGLIA, Luigi (compilador) Guerra e pace nell'Italia del Novecento, il Mulino, Bologna, 2006, pp. 251-290.

FORCELLA, Enzo y MONTICONE, Alberto (compiladores) Plotone di esecuzione. I processi della prima guerra mondiale, Laterza, Roma-Bari, 1968.

FRANZINA, Emilio, La storia (quasi vera) del Milite Ignoto, Donzelli, Roma, 2014.

FRANZINA, Emilio, A historia (quasi verdadeira) do soldado desconhecido, Martin Fontes, Sao Paulo, 2016.

GROTTANELLI, Cristiano (compilador) Gli occhi di Alessandro. Potere sovrano e sacralità del corpo da Alessandro Magno a Ceaucescu, Ponte alle Grazie, Firenze, 1990, pp. 120-153.

HARDIER, Thierry y JAGIELSKI, Jean, "Los cuerpos de los desaparecidos en la primera guerra mundial. El duelo imposible”, en Pasajes, Valencia, 2013-2014, No43, pp. 62-79.

ISNENGHI, Mario, Il mito della Grande Guerra, Bologna, il Mulino, 1989.

ISNENGHI, Mario, Le guerre degli italiani. Parole, immagini, ricordi 1848-1945, il Mulino, Bologna, 2005.

JELIN, Elizabeth (compiladora) Las conmemoraciones: las disputas en las fechas "in-felices”, Siglo XXI, Madrid, 2002.

JELIN, Elizabeth, Los trabajos de la memoria, Siglo XXI, Madrid, 2002.

JELIN, Elizabeth, La lucha por el pasado. Como construimos la memoria social, Siglo XXI, Buenos Aires, 2016.

KING, Alex, Memorials of the Great War in Britain. The Symbolism and Politics of Remembrance, Berg, Oxford 1998.

LABANCA, Nicola, "Una storia immobile? Messaggi alle forze armate italiane per il 4 novembre (19452000)”, en Quaderni Forum, Firenze, 2000, Anno XIV, No 3-4, pp. 69-99.

LABANCA, Nicola, Caporetto. Storia e memoria di una disfatta, il Mulino, Bologna, 2017.

LACAPRA, Dominick, Historia en tránsito. Experiencia, identidad, teoría crítica. Fondo de Cultura Económica, Buenos Aires, 2004. 
LABITA, Vito, "Il Milite Ignoto. Dalle trincee all'Altare della Patria", en BERTELLI Sergio y LUCCHINI, Stefano, A Caporetto abbiamo vinto, Rizzoli, 2017.

MINIERO, Alessandro, Da Versailles al Milite Ignoto. Rituali e retoriche della Vittoria in Europa (1919-1921), Istituto per la Storia del Risorgimento Italiano, Roma, 2008.

MONDINI, Marco, “La festa mancata. I militari e la memoria della Grande Guerra (1918-1923)”, en Contemporanea, Bologna, 2004, V. 4, pp. 555-579.

MONDINI, Marco y SCHWARZ Guri, Dalla guerra alla pace. Retoriche e pratiche della smobilitazione nell'Italia del Novecento, Cierre Edizioni, Vicenza, 2007.

MONTELEONE, Renato y SARASINI Pino, "I monumenti italiani ai caduti della grande guerra", en LEONI, Diego, y ZADRA, Camillo (compiladores) La grande guerra. Esperienze, memoria, immagini, Il Mulino, Bologna, 1986, pp. 631-662.

MOSSE, George L., The Nationalization of the Masses. Political Symbolism and Mass Movements in Germany from the Napoleonic Wars through the Third Reich, Howard Fertig, New York, 1975.

MOSSE, George L., Soldados caídos. La transformación de la memoria de las guerras mundiales, Prensas de la Universidad de Zaragoza, Zaragoza, 2016.

NORA, Pierre, Les lieux de mémoire, Montevideo, Trilce, 2008 (prólogo de José Rilla).

PLUVIANO, Marco, y GUERRINI, Irene, Le fucilazioni sommarie nella prima guerra mondiale, Gaspari, Udine, 2004.

POLLAK, Michael, Memoria, olvido, silencio. La producción social de identidades frente a situaciones límite, Al Margen, La Plata, 2006.

PORTELLI, Alessandro: "Memoria e identidad. Una reflexión desde la Italia post-fascista", en JELIN, Elizabeth y LANGLAND, Victoria (compiladoras) Monumentos, memoriales y marcas territoriales, Siglo XXI, Madrid, 2003.

POZZI, Enrico, "Il Duce e il Milite ignoto: dialettica di due corpi politici", en Rassegna italiana di Sociologia, Bologna, 1998, № 3, pp. 333-358.

PROCACCI, Giuliana, "Gli studi sulla prima guerra mondiale in Italia. Uso pubblico e condizionamenti culturali”, en Quaderni Forum, Firenze, 2000, Anno XIV, No 3-4, pp. 47-60.

ROCHAT, Giorgio, L'esercito italiano in pace e in guerra. Studi di storia militare, Rara, Milano, 1991.

ROCHAT, Giorgio, “Commemorare la Grande Guerra”, en Quaderni Forum, Firenze, 2000, Anno XIV, No 3-4, pp. 41-46.

SCHLEMMER, Thomas, Invasori, non vittime. La campagna italiana di Russia 1941-1943, Laterza, RomaBari, 2009. 
SMITH, Anthony, "Conmemorando a los muertos, inspirando a los vivos. Mapas, recuerdos y moralejas en la recreación de las identidades nacionales", en Revista Mexicana de Sociología, México, 1998, V. 60, No1, pp. 61-80.

STEVENSON, David, 1914-1918 Historia de la Primera Guerra Mundial, Debate, Buenos Aires, 2014.

TOBIA, Bruno, L'Altare della Patria, il Mulino, Bologna, 1998.

TOBIA, Bruno, "Dal Milite ignoto al nazionalismo monumentale fascista", en BARBERIS, Walter (compilador) Storia d'Italia. Annali 18. Guerra e pace, Einaudi, Torino, 2002, pp. 593-642.

TRAVERSO, Enzo, A sangre y fuego. De la guerra civil europea, 1914-1945, Prometeo, Buenos Aires, 2009.

VOVELLE, Michel, La mort et l'Occident de 1300 à nos jours, Galllimard, Paris, 1983.

WELCH, Steven R., "Commemorating 'Heroes of a Special Kind': Deserter monuments in Germany, Journal of Contemporary History, 2012, V. 47, No 2, pp. 370-401.

WINTER, Jay, Sites of Memory, sites of mourning. The Great War in European Cultural History, Cambridge University Press, Cambridge, 1995. 